\title{
Hubungan antara Tingkat Pendidikan Orang Tua dengan Kesadaran untuk Deteksi Dini Gangguan Pendengaran pada Bayi Baru Lahir
}

\author{
Relation between Parental Education Levels and Awareness \\ for Early Detection of Hearing Disorder in Newborns \\ Asti Widuri ${ }^{1 *}$, Bambang Edy Susyanto ${ }^{2}$, Supriyatiningsih ${ }^{3}$ \\ ${ }^{1}$ Bagian IImu THT, Fakultas Kedokteran dan Ilmu Kesehatan, Universitas Muhammadiyah Yogyakarta \\ 2 Bagian IImu Anak, Fakultas Kedokteran dan IImu Kesehatan, Universitas Muhammadiyah Yogyakarta \\ ${ }^{3}$ Bagian Ilmu Kandungan dan Kebidanan, Fakultas Kedokteran dan Ilmu Kesehatan, \\ Universitas Muhammadiyah Yogyakarta
}

DATA OF ARTICLE:

Received: 04 Sep 2018

Reviewed: 27 Sep 2018

Revised: 17 Okt 2018

Accepted: 21 Nov 2018

*CORRESPONDENCE: asti.widuri@umy.ac.id

DOI:

10.18196/mm.190122

TYPE OF ARTICLE: Research

\begin{abstract}
Abstrak: Gangguan pendengaran pada anak-anak di negara yang belum ada program deteksi gangguan pendengaran pada bayi baru lahir diawali dari kecurigaan saat anak terlambat bicara. Keterlambatan deteksi tersebut karena kurangnya pengetahuan orang tua terhadap perkembangan bicara dan bahasa sebelum anak berumur 2 tahun. Tujuan penelitian ini adalah melihat pengaruh tingkat pendidikan orang tua terhadap sikap/kesadaran tentang deteksi gangguan pendengaran pada bayi baru lahir. Penelitian dengan desain potong lintang menilai pendidikan orang tua dan sikap terhadap pemeriksaan deteksi gangguan pendengaran pada bayi baru lahir dilakukan pada orang tua/pasien klinik Asri Medical Centre Yogyakarta (AMC) bulan Juni-Juli 2018. Hasil penelitian menunjukkan 55 responden, 6 $(10,9 \%)$ dengan pendidikan sangat tinggi, $42(76,3 \%)$ dengan pendidikan tinggi, dan $7(12,7 \%)$ dengan pendidikan menengah. Hasil uji Chi-square menunjukkan tidak adanya pengaruh yang bermakna antara skor pendidikan orang tua, pengetahuan tentang tumbuh kembang anak, usia dan jumlah anak terhadap sikap orang tua pada program deteksi gangguan pendengaran pada bayi baru lahir. Tingkat pendidikan orang tua tidak berpengaruh pada sikap positif/tertarik pada program deteksi dini pemeriksaan pendengaran, sehingga dibutuhkan kebijakan pemerintah agar deteksi dini gangguan pendengaran berjalan optimal.
\end{abstract}

Kata kunci: Skrining Pendengaran; Pendidikan Orang tua; Bayi Baru Lahir; Perkembangan Bicara dan Bahasa

\footnotetext{
Abstract: Hearing loss in children in countries where there is no program for detecting hearing loss in newborns begins with suspicion when the child is late to speak. The late detection because parents have little knowledge to children speech and language development under 2 years old. Objective of this study is to determine relation of parent education toward their attitude about newborn hearing screening. A cross-sectional survey study using questionnaire about parental education and their attitude to newborn hearing screening was conducted on a purposive sample of parent and patient of Asri Medical Centre Yogyakarta on Juni-Juli 2018. From the 55 parents, 6 (10,9\%) were very high education, 42 (76,3\%) were high education, $7(12,7 \%)$ were medium education. Chi-square analysis shows that parental education, age, and number of children not significantly correlated with parent care of newborn hearing screening. There are no correlation of parent education with attitude or interest to newborn hearing screening. Therefore, there is a need to take government efforts to improve newborn hearing screening.
} 
Keywords: Hearing Screening; Parent Education; Newborn; Speech and Language Develoment

\section{PENDAHULUAN}

Ketulian merupakan gangguan sensori yang paling sering terjadi pada manusia termasuk pada bayi yang baru dilahirkan. Insidensi ketulian pada bayi baru lahir 0,001\% sampai 0,5\% dan meningkat pada bayi dengan faktor risiko mencapai $1 \%-5 \% .{ }^{1,2}$ Pengamatan terhadap anak dengan gangguan pendengaran yang terdiagnosis dan dilakukan intervenesi pada 6 bulan pertama kehidupan bayi akan mencegah dampak ketulian sehingga mencapai kemampuan bahasa, kosakata, ekspresi yang lebih baik daripada yang terdeteksi lambat. ${ }^{3}$ Amerika Serikat dan beberapa negara lain membuat kebijakan semua bayi baru lahir wajib dilakukan skrining pendengaran secara menyeluruh meskipun bayi tidak memiliki faktor risiko dan disahkan dengan UndangUndang (Joint Committee on Infant Hearing 2007). ${ }^{4}$

Idealnya pemberian intervensi pada anak tuna rungu saat mereka berusia kurang dari 2 tahun. Sesuai dengan teori perkembangan bahasa dimana saat tersebut merupakan masa emas untuk perkembangan bicara anak. Dilaporkan oleh Moeller et al. (2000), ${ }^{5}$ dimana anak tuna rungu di negara maju pada usia 6 bulan setelah terdeteksi seluruh anak tuna rungu dapat masuk ke program prasekolah yang dilakukan setiap hari dengan rata-rata umur saat masuk berusia 15 bulan.

Pemeriksaan Ottoacoustic emission (OAE) sangat sederhana dan tidak infasif dengan memasukkan "probe" di liang telinga. Alat OAE akan memberikan stimulus suara masuk ke liang telinga dan yang dinilai adalah respon yang muncul dari koklea. Hasil pemeriksaan dinyatakan dengan kriteria Pass (lulus) atau Refer (tidak lulus). Hasil Pass menunjukkan keadaan koklea baik, sedangkan hasil Refer artinya adanya gangguan koklea.5,6,7

Deteksi dini gangguan pendengaran masih menjadi tantangan di negara berkembang, Kumar (2015), 9 melaporkan rata-rata umur (bulan) kecurigaan pertama, diagnosis dan intervensi anak tuna rungu adalah 19,59 bulan, 24,82 bulan dan 29,28 bulan. Keterlambatan antara kecurigaan dengan diagnosis adalah 5,23 bulan dan jeda dari diagnosis sampai intervensi 4,46 bulan. $^{8}$

Sebanyak $70,48 \%$ anak tuna rungu baru dicurigai setelah berumur 1 tahun lebih dan hanya 1,6\% terdiagnosis gangguan pendengaran di bawah 6 bulan. Dengan demikian pengetahuan terhadap perkembangan bicara dan bahasa sangat penting bagi orang tua sehingga lebih cepat timbul kecurigaan jika kemampuan anaknya tidak sesuai. ${ }^{9}$
Program skrining ketulian universal pada bayi baru lahir yang ideal di Indonesia belum dapat dilaksanakan karena keterbatasan alat automated brain respon $(A B R)$ dan OAE. Selain alat tersebut hanya dimiliki oleh rumah sakit tertentu, terdapat kendala masih relatif tingginya biaya pemeriksaan, tidak semua rumah sakit mempunyai tenaga audiologist maupun dokter spesialis telinga hidung tenggorok, faktor sosial ekonomi masyarakat dan faktor kebijakan pemerintah.

Bagian THT Klinik AMC telah menyediakan pelayanan pemeriksaan skrining pendengaran bayi baru lahir dengan alat otoacoustic emission (OAE), akan tetapi untuk pemanfaatan sarana ini oleh masyarakat masih kurang. Tujuan dari penelitian ini adalah menilai pengetahuan orang tua tentang perkembangan bicara dan bahasa terhadap sikap perlunya pemeriksaan gangguan pendengaran pada bayi baru lahir.

\section{BAHAN DAN CARA}

Penelitian ini merupakan penelitian observational dengan pendekatan cross-sectional dimana peneliti menggunakan hasil kuesioner untuk menilai variabel bebas yaitu pendidikan orang tua dan variabel tergantung yaitu sikap/kesadaran tentang deteksi dini gangguan pendengaran pada bayi baru lahir.

Populasi yang digunakan dalam penelitian ini adalah pasien/orang tua pasien dengan kriteria inklusi orang tua bayi atau anak yang memeriksakan diri di klinik $A M C$ dan pasien/ibu hamil di poli kebidanan, dengan kriteria eksklusi pasien yang tidak mau menandatangani persetujuan/informed consent. Tingkat pendidikan di kategorikan menengah (SMA, D3), Tinggi (S1) dan sangat tinggi (S2/S3). Tingkat pengetahuan dikategorikan baik jika menjawab dengan benar lebih dari $60 \%$ pertanyaan tentang deteksi dini gangguan pendengaran. Analisis data menggunakan Chi-square untuk mengetahui signifikansi perbedaan antar kelompok tingkat pendidikan sangat tinggi, tinggi, menengah dan rendah.

\section{HASIL}

Responden penelitian ini diambil dari orang tua yang memiliki bayi dan balita yang memeriksakan anaknya di poli Anak dan pasien kebidanan dan kandungan di Poli Klinik AMC Yogyakarta selama bulan Juni-Juli 2018 yang bersedia mengisi kuesioner dengan menanda tangani surat persetujuan/ informed consent. Jumlah subyek penelitian ini adalah sebanyak 55 orang, dengan data demografi dan karakteristik umum responden dapat dilihat pada Tabel 1. 
Berdasarkan Tabel 1. dapat dilihat distribusi usia responden terbesar adalah kelompok usia 2030 tahun yaitu sebanyak 38 orang $(69,1 \%)$ yaitu ibuibu masa reproduksi, sedangkan 1,8 \% usia di bawah 20 tahun dan 29,1\% usia di atas 30 tahun. Tingkat pendidikan ibu yang paling banyak adalah pendidikan tinggi (D3 dan S1) sebanyak 42 orang (76,3\%), jumlah anak yang dimiliki ibu paling besar adalah 2 anak, yaitu sebanyak 33 orang $(45,8 \%)$ dan jumlah balita yang dimiliki ibu paling besar frekuensinya adalah o anak, yaitu sebanyak 23 orang (41,8\%).

Hasil kuesioner pengetahuan tentang perkembangan bicara dan bahasa dan sikap terhadap deteksi dini gangguan pendengaran dikategorikan baik jika jawaban benar lebih dari 75\% dan kurang jika kurang dari $75 \%$, sebagaimana terlihat pada Tabel 2.

Pada Tabel 2. dapat diketahui bahwa sebanyak 38 orang $(69,1 \%)$ mempunyai pengetahuan tentang perkembangan bicara dan bahasa dengan kategori baik, dan 38 orang $(69,1 \%)$ mempunyai kesadaran terhadap perlunya deteksi dini gangguan pendengaran pada bayi baru lahir. Kesadaran orang tua terhadap deteksi gangguan pendengaran pada bayi baru lahir dihubungkan dengan faktor-faktor karakteristik seperti pendidikan, usia, jumlah anak, dan tingkat pengetahuannya, didapatkan hasil pengujian uji statistiknya pada Tabel 3.

Tabel 3. menunjukkan bahwa secara keseluruhan tidak ada perbedaan kesadaran deteksi gangguan pendengaran atas faktor usia, pendidikan, jumlah anak dan tingkat pengetahuan terhadap perkembangan bicara dan bahasa secara statistik tidak menunjukkan perbedaan yang bermakna ( $p>0,05)$, sehingga dapat disimpulkan bahwa tingkat pendidikan orang tua tidak berpengaruh pada sikap positif/tertarik pada program deteksi dini pemeriksaan pendengaran.

Tabel 1. Karakteristik Subyek Penelitian Orang Tua Pasien Klinik AMC

\begin{tabular}{lcc}
\hline \multicolumn{1}{c}{ Karakteristik Subyek } & Frekuensi & $\begin{array}{c}\text { Persentase } \\
(\%)\end{array}$ \\
\hline Usia & 1 & 1,8 \\
$<20$ tahun & 38 & 69,1 \\
20-30 tahun & 16 & 29,1 \\
31-40 tahun & & \\
Pendidikan & 7 & 12,7 \\
Menengah (SMA) & 42 & 76,3 \\
Tinggi D3-S1 & 6 & 10,9 \\
Sangat Tinggi S2-S3 & & \\
Jumlah anak & 23 & 41,8 \\
0 & 22 & 40 \\
1 & 7 & 12,7 \\
2 & 3 & 5,5 \\
3 & & \\
\hline
\end{tabular}

Tabel 2. Hasil Skor Pengetahuan Orang Tua terhadap Perkembangan Bicara dan Bahasa Anak dan Kesadaran tentang Deteksi Dini

\begin{tabular}{lcc}
\hline \multicolumn{1}{c}{ Hasil } & Frekuensi & $\begin{array}{c}\text { Persentase } \\
(\%)\end{array}$ \\
\hline $\begin{array}{l}\text { Pengetahuan orang tua } \\
\text { Baik }\end{array}$ & 38 & $69,1 \%$ \\
Kurang & 17 & $30,9 \%$ \\
Kesadaran Deteksi & & \\
Baik & 38 & $69,1 \%$ \\
Kurang & 17 & $30,9 \%$ \\
\hline
\end{tabular}

Tabel 3. Tingkat Kemaknaan Uji Chi-square Kesadaran Deteksi Gangguan Pendengaran pada Bayi Baru Lahir Menurut Karakteristik Responden

\begin{tabular}{|c|c|c|c|c|}
\hline & Kesadaran & Deteksi & \multirow[t]{2}{*}{$x^{2}$} & \multirow[t]{2}{*}{$p$} \\
\hline & Baik & Kurang & & \\
\hline Usia & & & & \\
\hline$<20$ tahun & 1 & 0 & 2,181 & 0,336 \\
\hline 20-30 tahun & 24 & 14 & & \\
\hline 31-40 tahun & 13 & 3 & & \\
\hline Pendidikan & & & & \\
\hline Menengah (SMA) & 6 & 1 & & \\
\hline Tinggi D3-S1 & 27 & 15 & 2,833 & 0,418 \\
\hline Sangat Tinggi S2-S3 & 5 & 1 & & \\
\hline Jumlah anak & & & & \\
\hline 0 & 13 & 10 & & \\
\hline 1 & 17 & 5 & 3,305 & 0,347 \\
\hline 2 & 6 & 1 & & \\
\hline 3 & 2 & 1 & & \\
\hline Pengetahuan & & & & \\
\hline Baik & 28 & 10 & 1,215 & 0,270 \\
\hline Kurang & 10 & 7 & & \\
\hline
\end{tabular}

\section{DISKUSI}

Hasil uji statistik pengaruh tingkat pendidikan orang tua terhadap kesadaran/sikap tentang deteksi dini gangguan pendengaran pada bayi baru lahir tidak bermakna. Salah satu penyebabnya adalah angka prevalensi gangguan pendengaran yang rendah sehingga belum banyak dikenal oleh masyarakat umum. Hasil penelitian Moeller et al. (2006), ${ }^{5}$ pada dokter umum juga melaporkan adanya beberapa pendapat yang menyatakan deteksi gangguan pendengaran bahkan membuat kecemasan pada orang tua. Hasil survei yang dilakukan pada orang tua pasien di poliklinik anak dan pasien ibu hamil di poliklinik Kebidanan AMC Yogyakarta menunjukkan kesadaran perlunya deteksi dini gangguan pendengaran pada bayi baru lahir yang baik pada $38(69,1 \%)$ responden, hanya $6(11 \%)$ yang merasa kurang perlu jika bayi mereka normal tanpa faktor risiko. Hasil penelitian ini lebih rendah dibandingkan dengan peneliti- 
an lain tentang kesadaran deteksi dini dengan mengadakan survei melalui email terhadap dokter yang pada pelayanan primer didapatkan kesadaran pentingnya deteksi gangguan pendengaran pada bayi baru lahir sebesar $81,6 \%$, dengan sisanya merasa belum yakin. ${ }^{5}$

Hasil penelitian ini mendekati kesamaan dengan survei yang dilakukan oleh Mazlan (2018), ${ }^{10}$ yang melaporkan kesadaran terhadap program deteksi gangguan pendengaran pada bayi baru lahir pada tenaga medis yang bekerja di rumah sakit sebesar 70\%, angka kepedulian tertinggi pada profesi dokter spesialis THT, diikuti dokter spesialis anak, dan menurut pendapat perawat di bagian NICU justru pemeriksaan skrining gangguan pendengaran pada abyi baru lahir menimbulkan kecemasan pada orang tua bayi.

Pengetahuan yang baik tentang perkembangan bicara dan bahasa didapatkan pada 38 (69,1\%) responden. Hal ini dinilai masih rendah sehingga perlu upaya untuk memberikan pengetahuan sehingga terjadi perbaikan perilaku positif. Tingkat pendidikan tinggi pada $76,3 \%$ responden ternyata tidak berkorelasi dengan pengetahuan dan kesadaran deteksi dini. Seharusnya semakin seseorang berpendidikan tinggi akan memiliki pengetahuan yang lebih luas dan semakin mudah menerima hal-hal baru dan mudah belajar hal yang baru, tetapi ada kecenderungan seseorang tidak menguasai semua bidang, misalnya tenaga kesehatan lebih cepat mendapatkan pengetahuan sesuai bidangnya. ${ }^{10}$

Penelitian Mazlan (2018), ${ }^{10}$ menyebutkan bahwa responden dokter spesialis THT dengan skor pengetahuan tentang skrining pendengaran tertinggi $(74,9 \%)$ merupakan dokter yang memiliki dukungan tertinggi terhadap program skrining di rumah sakit tempat bekerja, sedangkan profesi lain yaitu dokter spesialis anak dan perawat NICU memiliki rata-rata skor pengetahuan di bawahnya. Hal ini menunjukkan bahwa pada tenaga medispun pengetahuan tentang dekteksi dini masih perlu ditingkatkan, terutama mengenai kapan perlu dilakukan skrining, bagaimana jika hasil skrining "refer", bagaimana evaluasi selanjutnya, apa pemeriksaan yang dibutuhkan, bagaimana intervensi yang tepat pada diagnosis gangguan pendengaran dan tim medis yang perlu bekerjasama dalam intervensi dini anak dengan gangguan pendengaran.

\section{SIMPULAN}

Pendidikan orang tua tidak berpengaruh pada sikap/kesadaran tentang deteksi dini gangguan pendengaran pada bayi baru lahir.

\section{DAFTAR PUSTAKA}

1. Kanne JT, Schaefer L, Perkins JA. Potential Pitfalls of Initiating A Newborn Hearing Screening Program. Arch Otolaryngol Head Neck Surg, 1999; 125 (1): 28-32.

2. Olusanya BO, Neonatal Hearing Screening and Intervention in Resource Limited Settings: An Overview. Arch Dis Child, 2012; 97 (7): 654-9.

3. Pimperton H, Kennedy CR. The Impact of Early Identification of Permanent Childhood Hearing Impairment on Speech and Language Outcomes. Arch Dis Child, 2012; 97 (7); 648-653.

4. Joint Committee on Infant Hearing. Year 2007 Position Statement: Principles and Guidelines for Early Hearing Detection and Interventions Programs. Pediatrics, 2007; 120 (4): 898-921.

5. Moeller MP, White KR, Shisler L. Primary Care Physicians' Knowledge, Attitudes, and Practices Related to Newborn Hearing Screening. Pediatrics, 2006; 118 (4): 1357-1370.

6. Goedert MH, Moeller MP, White KR. Midwives' Knowledge, Attitude, and Practice Related to Newborn Hearing Screening. J Midwifery Womens Health, 2011; 56 (2): 147-153.

7. Paludetti G, Ottaviani F, Fetoni AR, Zuppa AA, Tortorolo G. Transient Evoked Otoacustic Emissions (TEOAEs) in Newborns: Normative Data. Int J Pediatr Otorhinolaryngol, 1999; 47 (3): 235-241.

8. Shulman S, Besculides M, Saltzman A, Ireys H, White KR, Forsman I. Evaluation of the Universal Newborn Hearing Screening and Intervention Program. Pediatrics, 2010; 126 (Suppl1): S19-27.

9. Kumar S, Kolethekkat AA, Kurien M. Challenges in the Detection and Intervention of Childhood Deafness: Experience from A Developing Country. IJBR, 2015; (6) 01: 40-45

10. Mazlan R \& Min WS. Knowledge and Attitude of Malaysian Healthcare Professionals toward Newborn Hearing Screening Program. Malaysian J Public Health Med, 2018; Special Volume (1): 62-68 